\title{
The Effect of the Activities Enhanced Concerning Time Concept on Time Concept Acquisition of Children
}

\author{
Arzu Ergişi Birgül1 ${ }^{1, *}$, Elvan Şahin Zeteroglu ${ }^{2}$, Meral Taner Derman ${ }^{2}$ \\ ${ }^{1}$ Uludag University Kindergarten, Turkey \\ ${ }^{2}$ Basic Education Department, Faculty of Education, Uludağ University, Turkey
}

Copyright $\odot 2017$ by authors, all rights reserved. Authors agree that this article remains permanently open access under the terms of the Creative Commons Attribution License 4.0 International License

\begin{abstract}
The aim of this study is to examine the effect of the activities enhanced concerning time concept on time concept acquisition of children. The research is a quantitative study in experimental model with pretest posttest control group aiming to examine the effect of the activities enhanced concerning time concept on time concept acquisition of children. The study group of the research consists of 60 months old and older children who attend nursery schools within Uludağ University in Nilüfer County in the city centre of Bursa in 2016-2017 education year. 13 children in the experimental group and 16 children in the control group totally 29 children consist the study group of the research. The experimental and the control groups were performed pre-test and post-test. Within the research a pictorial form including 29 questions that were prepared by the researchers, was used as data gathering tool in order to measure the knowledge of the children about time concept. In order to see the difference between the experimental and the control group, Mann Whitney U Test was applied. It was determined that the activities enhanced regarding time concept affected the perception of the children about time concept in a positive way.
\end{abstract}

Keywords Child, Time Concept, Teacher, Preschool

\section{Introduction}

The effort of learning concepts, which is the core of thinking and learning, starts in the first years of life and continues intensely in the preschool education period. The concepts that the child will encounter in the future life are started to be learned in the preschool education period basically. Concept is described as the common name given to the event, idea and the group of objects that have similar aspects (Özyürek, 1983).

The concepts are separated into two groups which are abstract and concrete concepts. Concrete concepts; are the concepts of which physical aspects can be perceived through senses. Abstract concepts (defined) on the other hand; are the concepts of which aspects or connections between the concepts are not explained, the objects itself is not defined being showed concretely in other words they are the concepts that must be defined. Abstract concepts are always learned late and difficult. Children firstly perceive the outward features of the objects through their senses and then in parallel with cognitive development they start to give meaning to objects, events or formations. Thereby they try to perceive an abstract formation through concretising (Ünal, 2013).

Perceiving the time concept, which is an abstract concept, is a very complicated system considering the age of the children. Especially for the children within the preschool period perceiving the time concept is a little bit difficult. The acquisition of time is a social skill brought by birth. In addition since the time concept is an abstract concept, it is really difficult to perceive for children (Kol, 2010).

In preschool period the acquisition of the concepts is very important in terms of the academic success of the child. Thereby new cognitive abilities are gained and these abilities are put in action (Bütün Ayhan, Ergişi and Aral, 2013). As a matter of fact within the Ministry of National Education Preschool Education Curriculum it is aimed to acquire concepts such as size, amount, emotions, place, colour, direction, shape, sense, number and some other by the children. Within the time concept category the concepts of "before-now-after, day-night, morning-noon-evening, yesterday-today-tomorrow, and year" are included (MEB, 2013). However the studies and observations indicate that these concepts are not acquired adequately in preschool education institutions. It is stated that some of these concepts are used more in the level of information rather than conceptual content; they are integrated with the deeds and actions (after-noon nap, lunch, breakfast, dinner etc.). Also it is suggested that the teachers have inadequate levels of knowledge concerning concept teaching process (Ünal, 2013).

The researchers state that the children under the age of 
three have a primitive feeling of time making them assume the time, and as they grow their sensitiveness for time increases also the children around three have the knowledge of time gap (Droit-Volet, 2011). A child's arranging his or her behaviours according to time emerges at the age of 4-6 (Pouthas, Droit and Jacquet, 1993). When the development of the use of time in the speeches of the children is examined it is seen that when they are around 12 months old they use commands and past tense in their verbal expressions. When the children are around 20 months old they use present continuous tense; between the months 21-30 future tense, around 25-27 months they start to use the optative and around 25-27 they use different forms of past perfect tense. Afterwards the expressions that state present tense and subjunctive are produced. The necessitative mood is seen around 30 months. Although the development of the use of time is this way it is seen that the children make a lot of mistakes when they are telling their actions concerning future, present and past, using the time expressions and using the tense suffixes (Günay, Tokgöz and Duman, 2004). Many experiences are acquired by means of school and these experiences affect the academic lives of the children in their future positively (Bjorklund, 1995). Therefore it is necessary to make special studies that enable children acquire time concept within the preschool education period.

Time concept emerges within the first periods of childhood in a way that from simple to complex. While children can learn the difference between day and night more easily since they can concretise it at the conceptual level, they cannot learn the difference between evening and night or morning and noon. For this they need to grow a little bit more (Şen, 2004). Presenting the time concept to children with various activities is quite effective in terms of acquisition of time, supporting academic motivation, and realizing the time units such as hour, day, month, year, and season. Rich stimulating experiences help the children mature within the process of cognitive development. A stimulating environment eases the formation of new stimulations in the child. Within the activities regarding the development of time concept using concrete materials occupies an important position especially in supporting the cognitive development (Safran and Şimşek 2009).

When the literature is examined it is seen that the studies concerning conceptual development in preschool period children is more than the studies regarding the acquisition of time concept. Therefore this study has importance in terms of its contribution to the literature. The purpose of this study is to examine the effect of the activities enhanced concerning time concept on the acquisition of time concept for children.

\section{Method}

This research was carried out in order to examine the effect of the activities enhanced concerning time concept on time concept acquisition of children. The aim of the research is to search how the activities applied in preschool education institutions affect the children's time concept.

The Pattern of the Research: The research is a quantitative study in experimental model with pretest posttest control group aiming to examine the effect of the activities enhanced concerning time concept on time concept acquisition of children.

The Study Group: The study group of the research consists of 60 months old and older children who attend nursery schools within the body of Uludağ University in Nilüfer County in the city centre of Bursa in 2016-2017 education year. Within the research considering the fact that the children would be affected by the activities applied regarding the development of time concept indirectly, the children in the experimental and the control group was chosen from the same school yet from the classes with a certain distance. 13 children in the experimental group, 16 children in the control group totally 29 children consisted the study group of this research. The experimental and the control group were performed pretest and posttest (Büyüköztürk, 2013).

Data Gathering Tools: Within the research as data gathering tool a pictorial form, which included 29 questions prepared by researchers, was used to measure the knowledge of the children about time concept. Every correct answer was evaluated as 1 point and every incorrect answer was evaluated as 0 .

The planning and the application of the activities regarding time concept: While preparing the activities regarding time concept the Ministry of National Education Preschool Education Curriculum was utilized. The acquisitions and the indicators regarding the supporting of time concept were determined appropriately for the development of the children. Within the scope of the acquisitions and the indicators determined, activities that were enhanced with time concept and reinforced with materials prepared by the researchers were organized to be applied one hour a week for 10 weeks. During the preparation of the program and the material factors that support the cognitive development of the children such as drawing the attention of the children, feeling themselves within the activity, expressing the ideas and emotions easily, stating opinion about time concept were aimed. Therefore while preparing the curriculum the interests and the needs of the children were considered. The activities in which the children can express themselves easily, they can perceive time concept effortlessly, they can work both in groups and individually, and supporting their creativity were included. In order to evaluate the development of the children in the experimental and the control group were applied the "Pictorial Form" which was prepared by the researchers as pretest. The activities regarding time concept were applied to the experimental group one hour a week for 10 weeks between the dates of 3rd of April 2017 
and 10th of June 2017. The children within the experimental group attended the educations of the Ministry of National Education Preschool Education Curriculum when the activities were not performed. The children in the control group on the other hand continued their education within the scope of the Ministry of National Education Preschool Education Curriculum. After completing the applications of the activities regarding time concept the experimental and the control groups were applied "Pictorial Form".

Before the scale was used, communication with Sayın Kalbiye Yalaz, who made the standardization of the scale, was taken, necessary information about the factors such as the application of the scale and the duration of application were obtained. The study was conducted with children who attended pre-school institutions and showed normal development. During the study, the children continued to be observed. The test interval between the pre-test and the post-test was set at two months since children with normal development were selected. Eratay (2009) conducted a study on the adequacy of the Montessori Method in children with disabilities ( 2 children) and non-handicapped children (13 children) who were attending the school before and gave a two month period between pre-test and post-test. After the posttest applications were completed, the activities applied to the experimental group were applied to the control group. Thus, the positive effects of these activities are also benefited by the children in the control group.

The Analyse of the Data: The required statistical analyses were made recording the "Pictorial Form" scores of the children participated in the research from pretest and posttest in the computer. The analyses were made with 15.0 SPSS statistic program. Within the analysis of the data gathered with "Pictorial Form" whether parametric and nonparametric analyses would be used in order to test the aims of the research was determined according to test of normality. Whether the scores of the children from the "Pictorial Form" indicate normal distribution or not was examined with Shapiro-Wilk Test since the study group was less than fifty ( experimental group 13- control group 16 totally 29). The significant result of the Shapiro-Wilk
Test indicates that the scores of the children from "Pictorial Form" do not indicate normal distribution. Therefore in order to see the difference between the experimental and the control group Mann Whitney U Test was applied (Büyüköztürk 2013).

Table 1. The results of the test of normality and descriptive statistics of the pretest and posttest that belong to the "Pictorial Form" of the children in the experimental and control group

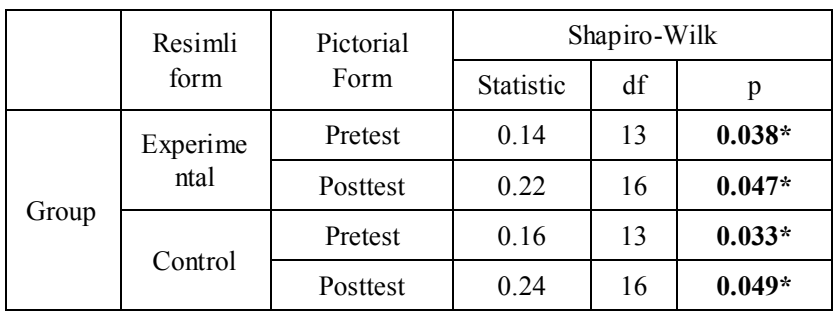

$* \mathrm{p}<.005$

When Table 1 is examined it is seen that the score averages of the pretest and posttest of the experimental group that belong to the "Pictorial Form" indicate deviation $(* \mathrm{p}<.05)$.

The scores obtained that belong to the "Pictorial Form" were evaluated with nonparametric statistics. The difference between score averages of pretest and posttest was analysed with Mann Whitney U Test (Büyüköztürk, 2013).

\section{Findings}

The findings obtained within the research were presented in tables and discussed using literature data.

When Table 2 is examined it is seen that the experimental group pretest score averages that belong to the "Pictorial Form" were $\mathrm{X}=37.06$, and control group pretest score averages were $X=38.25$. It is concluded that there was not a significant difference between the score averages of the experimental and the control group $[\mathrm{U}=12.5, \mathrm{p}>086]$. Not including the activities regarding the acquisition of time concept within the daily plan adequately and not involving the concrete materials in the presentation of the activities regarding time concept can be a reason for this.

Table 2. Mann Whitney U Test and standard deviations of the pretest score averages that belong to the "Pictorial Form" of the children in the experimental and the control group

\begin{tabular}{|c|c|c|c|c|c|c|c|c|}
\hline & & $\mathrm{n}$ & $\mathrm{X}$ & $\mathrm{sd}$ & Line Average & Line Total & Mann Whitney U & $\mathrm{p}$ \\
\hline \multirow{3}{*}{ Pretest } & Experimental & 13 & 37.06 & 4.67 & 16.03 & 51.23 & & \multirow{2}{*}{12.5} \\
\cline { 2 - 10 } & Control & 16 & 38.25 & 3.02 & 19.16 & 36.52 & & .086 \\
\hline
\end{tabular}

$* \mathrm{p}<.005$

Table 3. Mann Whitney U Test and standard deviations of the posttest score averages that belong to the "Pictorial Form" of the children in the experimental and the control group

\begin{tabular}{|c|c|c|c|c|c|c|c|c|}
\hline & & $\mathrm{n}$ & $\mathrm{X}$ & $\mathrm{sd}$ & Line Average & Line Total & Mann Whitney U & $\mathrm{p}$ \\
\hline \multirow{3}{*}{ Posttest } & Experimental & 13 & 39.06 & 6.02 & 18.12 & 54.48 & \multirow{2}{*}{9.53} & \multirow{2}{*}{003} \\
\cline { 2 - 10 } & Control & 16 & 41.23 & 4.28 & 21.01 & 38.21 & & \\
\hline
\end{tabular}


When Table 3 is examined posttest score averages that belong to the "Pictorial Form" of the children in the experimental group which were applied activity program regarding time concept were $X=39.06$. The posttest score averages of the children in the control group which were not applied activity program regarding enhanced time concept were $X=41.23$. There is a significant difference between the posttest score averages of the experimental and the control group [U=9.53, $\mathrm{p}<003]$. Although the score averages of the children in the experimental group were low before the education it is seen that the posttest score averages were higher on behalf of experimental group. This situation can be interpreted as the activities enhanced regarding time concept affect the time concept perception of the children in a positive way.

\section{Results, Conclusions and Recommendations}

The study performed indicates that in preschool period the education given with the activities enhanced in terms of time concept and using concrete materials regarding the development of time concept, develops the time concept acquisition of the children and effective in their learning. When the literature is examined it is seen that there are studies in which similar findings are included. Çelik, (2005) stated that Time Concept Educational Toy Program is effective in teaching the time concept to the 6 year old children who attend preschool education institutions. Within the research carried out by Yilmaz (2005) a program which was based on the creative activities regarding the teaching of time concept to 5-6 year old children and it was determined that this program was effective in teaching time concept. In the study of Kurtuluş (1999), which was carried out in order to teach concepts (time concept) to the 5-6 year old children, who attend preschool education institution, it is concluded that the enhancing the education program increases the concept (time concept) development. In the study of $\operatorname{Er}$ (2008) 36 children, who were at the age of 5-6 attending preschool education institution, participated and their time concept development was examined using Turkish Language Activities Enhanced with Time Concept". In the study it is concluded that there was significant difference between posttest scores of the experimental and the control group. Panagiotakopoulos and Ioannidis (2002) in their study in which totally 374 children participated, examined the effect of the education presented to the children with different techniques on the acquisition of fundamental time concepts. In their study they concluded that in the development of time concept the education given with different techniques was more effective compared to the one given with traditional ways and there was difference between experimental and control groups. In the study of Kol (2012) 30 experimental and 30 control totally 60 children participated and a different educational application method was chosen. Within this study, which was carried out regarding the reinforcement of the concept of space and time, including computer aided education, emphasised the importance of computer aided education which is a different technique in the acquisition of space and time concept. Also it was concluded that there was a significant difference between the children who had a supportive education of time concept with various materials and the ones who never had this kind of education. As it is seen the studies in the literature support the conclusion of this study.

This research was carried out in order to examine the effect of the activities enhanced concerning time concept on time concept acquisition of children. In the research it is concluded that between the experimental and the control group there was a significant difference concerning the pretest and posttest score averages of the education program carried out regarding time concept.

As a result of the study within the scope of the findings obtained, the researchers can be given various recommendations. This research discussed time concept using concrete materials (illustrated cards). The effect of different education models on the development of time concept of the children can be examined.

Through in service training the activities enhanced regarding time concept or various educational programs can be introduced and the training of preparing concrete materials can be given to teachers. In preschool period the number of the scales developed regarding measuring time concept is limited. Studies regarding increasing the number of the scales for measuring time concept can be performed. Expanding the studies regarding the fundamental field of time concept similar studies can be performed with younger children. Similar studies can be performed applying different variables to other population and sample groups.

\section{REFERENCES}

[1] Bjorklund F. (1995). Children's thinking (2nd ed.). Brooks/Cole Company. CA.

[2] Bütün Ayhan, A., Ergişi A. ve Aral, N. (2013). “A Study on the Effects of Socioeconomic Status on the concept Development of Kindergarten Children", The International Journal of Early Childhood Learning, 19(2), 1-13.

[3] Büyüköztürk, Ş. (2013). Data analysis handbook for social sciences. Statistics research design SPSS applications and comments. Ankara: Pegem Publishing.

[4] Çelik, C. (2005). Determining the effects of play materials on concept development of preschool children, Unpublishing Master Thesis. Selçuk University Social Sciences Institute, Konya. 
[5] Droit-Volet, S. (2011). "Child and time". Multidisciplinary aspects of time and time perception (pp. 151-172). Springer-Verlag: Berlin Heidelberg.

[6] Er, H.D. (2008). Analysing the effects of Turkish language activies enriched with the concept of time upon the 5-6 age children's development of the concept of time. Unpublishing Master Thesis. Selçuk University Social Sciences Institute, Konya.

[7] Eratay, E. (2009). Efficiency of Montessori Method, 19th National Special Education Congress. October 22-24, Marmaris.

[8] Günay, V. D., Tokgöz, İ. ve Duman, F. (2004). "Time Concept in Child Language" 2nd National Language and Speech Disorders Congress Book, 71-80, 28-30 May 2004, Prepared for publication by: Prof. Dr. S. Seyhan Topbaș, Ankara: Kök Publications.

[9] Kol, S. (2010). Developing the achievement test to measure the concepts of time and space acquired in preschool period. International Conference on New Trends in Education and Their Implications. 10-11 November, 894-902.

[10] Kol, S. (2012). Gaininig the effect of time and space concepts to six-year-old children in computer assisted instruction (CAI), Unpublishing DoctoralThesis. Selçuk University Social Sciences Intitute, Konya.

[11] Kurtuluş, E. (1999). Learning to conception (time) of pre-school children in ages $5-6$ by creative activities. Yayımlanmış Yüksek Lisans Tezi. Marmara University
Educational Sciences Institute, İstanbul.

[12] MEB (2013). Preschool Education Program, Ministry of National Education General Directorate of Basic Education, Ankara.

[13] Panagiotakopoulos, C.T. and Ioannidis, G.S. (2002), Assessing Children's Understanding of Basic Time Concepts Through Multimedia Software, Computers \& Education, 38, 331-349.

[14] Pouthas, V., Droit, S., \& Jacquet, A. Y. (1993). Temporal experiences and time knowledge in infancy and early childhood. Time \& Society, 2 (2), 199-218.

[15] Safran, M. ve Şimşek, A. (2009). The development of time perception in children, Journal of International Social Research, 2 (6), 542-548.

[16] Şen, S. (2004). Examination of short story and fairy tale books about preschool children's language and concept development, Adnan Menderes University, Project no: EGF 01002 .

[17] Ünal, K. (2013). Investigating Instructional Process of Morning, Afternoon and Evening Concepts for Preschool Students, Middle Eastern \& African Journal of Educational Research, 5, 83-95.

[18] Y1lmaz, S. (2005). Teaching the time concept to 5-6 year old group preschool children who attend nursery schools. Unpublishing Master Thesis. Selçuk University Social Sciences Institute, Konya. 